\title{
Prognonstic impact of renin-angiotensin system blockade in localised upper-tract urothelial carcinoma
}

\author{
N Tanaka', A Miyajima*,', E Kikuchi', K Matsumoto',2, M Hagiwara', H Ide',3, T Kosaka', T Masuda ${ }^{3}$, \\ S Nakamura ${ }^{2}$ and M Oya'
}

'Department of Urology, Keio University School of Medicine, 35 Shinanomachi, Shinjuku-ku, Tokyo I60-8582, Japan; '2Department of Urology, Saiseikai Central Hospital, Tokyo, Japan; ${ }^{3}$ Department of Urology, Saitama Municipal Hospital, Saitama, Japan

BACKGROUND: The potential role of the renin-angiotensin system (RAS) in the promotion of tumour growth has been investigated, and the administration of RAS inhibitors, such as angiotensin-converting enzyme inhibitors (ACEls) or angiotensin II receptor blockers (ARBs), may improve disease control in malignancy. We investigated the prognostic impact of RAS inhibitors by analysing data from patients with upper-tract urothelial carcinoma (UTUC).

METHODS: A total of 279 patients who underwent nephroureterectomy for localised UTUC (pTa-3NOM0) were identified at our three institutions. We retrospectively investigated the prognostic outcomes following nephroureterectomy in patients administered or not administered ACEls or ARBs.

RESULTS: The median follow-up period was 3.4 years. RAS inhibitors were administered to 48 patients ( I 7.2\%). Multivariate analysis showed that the appearance of pathological T3, positive lymphovascular invasion, and no RAS inhibitor administration $(P=0.027$ $\mathrm{HR}=3.14$ ) were independent risk factors for a decrease in subsequent metastasis-free survival. The 5-year metastasis-free survival rate was $93.0 \%$ in patients who administered RAS inhibitors, and $72.8 \%$ in their counterparts who did not $(P=0.008)$.

CONCLUSION: The absence of RAS inhibitor administration was an independent risk factor for subsequent tumour metastasis in patients with localised UTUC. We propose RAS inhibitors may be a potent choice as an effective treatment following nephroureterectomy.

British Journal of Cancer (2012) 1 06, 290-296. doi:10.1038/bjc.20II.565 www.bjcancer.com

Published online 20 December 2011

(C) 2012 Cancer Research UK

Keywords: renin-angiotensin system; angiotensin II-converting enzyme inhibitor; angiotensin II receptor blocker; upper-tract urothelial carcinoma

Upper-tract urothelial carcinoma (UTUC) is relatively uncommon, accounting for approximately $5 \%$ of urothelial malignancies and $10 \%$ of all renal tumours (Rouprêt et al, 2011; Jemal et al, 2011). Surgical resection such as nephroureterectomy with excision of a bladder cuff is the standard treatment for localised UTUC; however, contemporary oncological outcomes still remain poor owing to the high risk of systemic recurrence after operation. Many patients with localised UTUC are stage T3 or greater at the time of surgery (Holmang and Johansson, 2005; Matin et al, 2010), and at least $20-25 \%$ of these patients may already be considered to have lymph node involvement (Miyake et al, 1998; Kondo et al, 2007). Even after radical surgery, 5-year disease-specific survivals ranging between $50 \%$ and $80 \%$ have been demonstrated (Hall et al, 1998; Margulis et al, 2009; Favaretto et al, 2010). Therefore, an important goal of further research is to identify potent therapeutic applications in an attempt to improve disease control following surgery in patients with localised UTUC.

Angiotensin II (Ang II) is a key biological peptide in the reninangiotensin system (RAS). There are two major subtypes of Ang II

*Correspondence: Dr A Miyajima; E-mail: akiram@sc.itc.keio.ac.jp Received 26 August 2011; revised 18 November 201 I; accepted 22 November 201 I; published online 20 December $201 \mathrm{I}$ receptors; Ang II type 1 receptors (AT1R) and type 2 receptors (AT2R). Concern regarding the potential role of Ang II in angiogenesis and promotion of tumour growth has been growing in the past few decades (Egami et al, 2003; Juillerat-Jeanneret et al, 2004; Ager et al, 2008; George et al, 2010), and Lever et al reported the first clinical evidence that long-term Ang II blockade might have a protective effect against carcinogenesis (Lever et al, 1998). We previously showed that Ang II-AT1R signalling led to potent induction of vascular endothelial growth factor, and RAS inhibition led to an anti-angiogenic effect in urogenital malignancies (Miyajima et al, 2002; Kosugi et al, 2006; Kosaka et al, 2007; Tanaka et al, 2010). Using human bladder cancer specimens, we also confirmed that tumours with a high grade and/or high stage would potentially have higher AT1R expression in urothelial cancer cells (Shirotake et al, 2011b). Thus, we propose that administration of RAS inhibitors, such as angiotensin-converting enzyme inhibitors (ACEIs) or Ang II receptor blockers (ARBs), may improve the control of urothelial malignancies.

In the present study, we retrospectively reviewed the data of 265 patients who underwent nephroureterectomy for localised UTUC. We examined the association between clinicopathological parameters and the use of ACEIs or ARBs, and then analysed outcomes to identify the prognostic impact of RAS inhibitor administration in UTUC. 


\section{PATIENTS AND METHODS}

After institutional review board approval, medical records from between 1995 and 2009 archived at Keio University Hospital, Saiseikai Central Hospital, and Saitama Municipal Hospital were retrospectively reviewed. During this period, more than 300 cases underwent nephroureterectomy for UTUC at our three institutions. Five patients with distant metastasis at diagnosis, 14 with pT4 and/or positive lymph node involvement, and four with concomitant muscle-invasive bladder cancer were excluded from study. We identified a total of 284 patients with localised UTUC (pTa-3N0M0) in our study population. After excluding five patients who began to administer RAS inhibitors following nephroureterectomy, the remaining 279 patients were included in the subsequent analyses. The median follow-up for all cohorts was 3.4 years (range, $0.2-15$ years).

Open nephroureterectomy was performed in 215 patients (77.1\%), whereas the remaining 64 patients $(22.9 \%)$ underwent laparoscopic nephroureterectomy. Dissection of regional lymph nodes was performed in patients with nodes that were found to be enlarged in a pre-operative evaluation or in those who were suspected for having enlarged nodes at intraoperative inspection. Extended lymphadenectomy was not routinely performed. CDDP-based neoadjuvant and adjuvant chemotherapy regimens were administered to $3(1.1 \%)$ and 43 patients (15.4\%), respectively. Post-operative adjuvant radiotherapy regimens were not routinely used.

Patients were assessed by urine cytology and cystoscopy every 3 months for 2 years following nephroureterectomy, every 6 months for the next 3 years, and then every 6-12 months thereafter. CT, and/or MRI, and/or excretory urograms were also performed every 6 months for 5 years and annually thereafter. In Japan, patients have equal access to standard care under the comprehensive Japanese national health-insurance programme, and thus there were most likely no dramatic differences in the clinical course of treatments and follow-up in the study population.

The independent variables used in the present study were patient age, gender, history of cardiovascular disease, chronic kidney disease (CKD), diabetes, hypertension, the use of antihypertensive drugs at nephroureterectomy, status of perioperative chemotherapy, tumour location, tumour length, and pathological features (tumour grade, pathological $\mathrm{T}$ stage, appearance of lymphovascular invasion (LVI), and the presence of concomitant carcinoma in situ (CIS)) in surgical specimens.

All patients were interviewed by attending physicians at least two times, such as during hospitalisation at the time of diagnosis and at nephroureterectomy, and data concerning their history of disease and medications administered were routinely collected in the study. Moreover, data concerning their medication after surgery was obtained from medical records and interviews by physicians. The use of antihypertensive drugs at nephroureterectomy was reviewed, focusing on the use of RAS inhibitors (ACEIs or ARBs) and other agents (calcium-channel blockers, $\beta$-blockers, and diuretics). CKD was defined as an eGFR $<60 \mathrm{ml} / \mathrm{min} / 1.73 \mathrm{~m}^{2}$ according to National Kidney Foundation guidelines (National Kidney Foundation, 2002) and calculated using the four-variable MDRD study equation (Levey et al, 1999). Tumour location was divided into two areas: the renal pelvis or ureter based upon the location of the dominant lesion. Tumour size was measured using the maximum diameter of the tumour. With regard to the pathologic disease stage, all neoplasms were classified according to the 2002 TNM staging system. Histologic grades were assigned according to the three-tiered World Health Organization classification. LVI was defined as the presence of tumour cells within an endotheliumlined space without underlying muscular walls. The presence of concomitant CIS was also assessed in every representative section.

The associations between the clinicopathological parameters of a patient and the status of RAS inhibitors were analysed. These associations were validated by the $\chi^{2}$-test or Mann - Whitney
$U$-test. Metastasis-free, disease-specific, and overall survival rates were estimated using the Kaplan-Meier method and were compared by the log-rank test. Survival time was calculated using the data from the operation. Multivariate analysis was performed using the Cox proportional hazards model with stepwise forward selection. Differences among groups were regarded to be significant when $P<0.05$. These analyses were performed with the SPSS version 17.0 statistical software package.

\section{RESULTS}

The mean age of all cohorts was 69 years (range, 36-92 years). Males accounted for $74.2 \%$ (207 patients) and females $25.8 \%$ ( 72 patients). Table 1 presents a summary of the clinicopathological parameters for the 279 patients. Of the 279 patients, 128 were

Table I Clinicopathological parameters in the 279 study patients

\begin{tabular}{|c|c|}
\hline Characteristic & No. of patients (\%) \\
\hline \multicolumn{2}{|l|}{ Age } \\
\hline$<70$ years & $130(46.6)$ \\
\hline$\geqslant 70$ years & $149(53.4)$ \\
\hline \multicolumn{2}{|l|}{ Gender } \\
\hline Male & $207(74.2)$ \\
\hline Female & $72(25.8)$ \\
\hline \multicolumn{2}{|c|}{ Cardiovascular disease } \\
\hline Yes & $34(12.2)$ \\
\hline No & $245(87.8)$ \\
\hline \multicolumn{2}{|c|}{ Chronic kidney disease } \\
\hline Yes & $5 \mid(\mid 8.3)$ \\
\hline No & $228(81.7)$ \\
\hline \multicolumn{2}{|l|}{ Diabetes } \\
\hline Yes & $36(12.9)$ \\
\hline No & $243(87.1)$ \\
\hline \multicolumn{2}{|l|}{ Hypertension } \\
\hline Yes & $128(45.9)$ \\
\hline No & $15 \mid(54.1)$ \\
\hline \multicolumn{2}{|c|}{ Perioperative chemotherapy } \\
\hline Yes & $45(16.1)$ \\
\hline No & $234(83.9)$ \\
\hline \multicolumn{2}{|l|}{ Tumour location } \\
\hline Renal pelvis & $156(55.9)$ \\
\hline Ureter & $123(44.1)$ \\
\hline \multicolumn{2}{|l|}{ Tumour length } \\
\hline$<30 \mathrm{~mm}$ & $173(62.0)$ \\
\hline$\geqslant 30 \mathrm{~mm}$ & $106(38.0)$ \\
\hline \multicolumn{2}{|l|}{ Tumour grade } \\
\hline $\mathrm{Gl} / 2$ & $108(38.7)$ \\
\hline G3 & $171(61.3)$ \\
\hline \multicolumn{2}{|c|}{ Pathological T stage } \\
\hline$<$ pT3 & $126(45.2)$ \\
\hline$\geqslant p T 3$ & $153(54.8)$ \\
\hline \multicolumn{2}{|c|}{ Lymphovascular invasion } \\
\hline Negative & $170(60.9)$ \\
\hline Positive & $109(39.1)$ \\
\hline \multicolumn{2}{|l|}{ Concomitant CIS } \\
\hline Negative & $223(79.9)$ \\
\hline Positive & $56(20.1)$ \\
\hline
\end{tabular}

Abbreviation: $\mathrm{CIS}=$ carcinoma in situ. 
Table 2 Number of patients receiving antihypertensive drugs

\begin{tabular}{lc}
\hline Characteristic & No. of patients \\
\hline ACEls & 5 \\
Enalapril & 3 \\
Cilazapril & 1 \\
Perindopril & 1 \\
ARBs & \\
Valsartan & 43 \\
Candesartan & 16 \\
Losartan & 15 \\
Telmisartan & 5 \\
Olmesartan & 4 \\
Calcium-channel blockers & 3 \\
$\beta$-blockers & \\
Diuretics & 90 \\
\hline
\end{tabular}

Abbreviations: ACEls = angiotensin-converting enzyme inhibitors; $A R B s=$ angiotensin I receptor blockers.

diagnosed with hypertension, and a total of 113 patients $(40.5 \%)$ received medications for hypertension at nephroureterectomy. Of these patients, $48(17.2 \%)$ used ACEIs $(N=5)$ or ARBs $(N=43)$. Other antihypertensive drugs included calcium-channel blockers $(N=90), \beta$-blockers $(N=15)$, or diuretics $(N=7)$. The type of ACEI or ARB at surgery is shown in Table 2. Of 48 patients, 45 continued to administer RAS inhibitors with a mean duration of 4.5 years following nephroureterectomy (range, 0.4-13 years). Patient data concerning the duration of RAS inhibitor administration following surgery was not available for three patients.

During the follow-up, tumour metastasis was observed in 61 patients $(21.9 \%)$ and 49 patients $(17.6 \%)$ died of disease. Table 3 presents a list regarding the use of ACEIs and ARBs. Even though patients receiving ACEIs or ARBs had higher incidences of cardiovascular disease and administration of other antihypertensive drugs, no significant difference was found between patient age, gender, the presence of CKD and diabetes, status of perioperative chemotherapy, tumour location, tumour length, and pathological features in surgical specimens. Using KaplanMeier analysis, we estimated the metastasis-free and diseasespecific survival rates in patients administered or not administered ACEIs and ARBs (Figure 1A and B). The 5-year metastasis-free survival rate was $93.0 \%$ in patients administered ACEIs and ARBs and $72.8 \%$ in their counterparts $(P=0.008)$, and the 5-year disease-specific survival rate was $93.2 \%$ in patients administered ACEIs and ARBs and $79.2 \%$ in their counterparts $(P=0.028)$, respectively.

Univariate and multivariate analyses were performed to determine risk factors for subsequent tumour metastasis (Table 4). Univariate analysis revealed that patient age $(P=0.048)$, no ACEI or ARB administration $(P=0.013)$, the use of perioperative chemotherapy $(P=0.009)$, tumour grade $(P=0.001)$, pathological T stage $(P<0.001)$, and LVI $(P<0.001)$ were significant risk factors for predicting subsequent tumour metastasis. On multivariate analysis controlling these significant variables, no ACEI or ARB administration $(P=0.027 \mathrm{HR}=3.14)$ was an independent risk factor for a decrease in subsequent metastasis-free survival in addition to other prognostic indicators such as the appearance of pathological T3 $(P=0.001, \mathrm{HR}=3.50)$ and positive LVI $(P=0.013$, $\mathrm{HR}=2.10)$ in surgical specimens.

Next, we performed univariate and multivariate analyses to determine risk factors for disease-specific survival (Table 4). Univariate analysis revealed that the presence of CKD $(P=0.014)$, no ACEI or ARB administration $(P=0.039)$, tumour grade $(P=0.003)$, pathological T stage $(P<0.001)$, and LVI $(P<0.001)$ were significant risk factors for a decrease in subsequent disease-specific
Table 3 Clinicopathological parameters in 279 patients according to ACEI or ARB administration

\begin{tabular}{|c|c|c|c|}
\hline Characteristic & $\begin{array}{c}\text { Patients not } \\
\text { administered } \\
\text { ACEI/ARB (\%) }\end{array}$ & $\begin{array}{c}\text { Patients } \\
\text { administered } \\
\text { ACEI/ARB (\%) }\end{array}$ & $P$-value \\
\hline No. of patients & 231 & 48 & \\
\hline Age & & & 0.470 \\
\hline$<70$ years & $107(46.3)$ & $23(47.9)$ & \\
\hline$\geqslant 70$ years & $124(53.7)$ & $25(52.1)$ & \\
\hline Gender & & & 0.476 \\
\hline Male & $172(74.5)$ & $35(72.9)$ & \\
\hline Female & $59(25.5)$ & $13(27.1)$ & \\
\hline Cardiovascular disease & & & 0.016 \\
\hline Yes & $23(10.0)$ & II (22.9) & \\
\hline No & $208(90.0)$ & $37(77.1)$ & \\
\hline Chronic kidney disease & & & 0.533 \\
\hline Yes & $42(18.2)$ & $9(18.8)$ & \\
\hline No & $189(81.8)$ & $39(81.2)$ & \\
\hline Diabetes & & & 0.138 \\
\hline Yes & $27(\mid 1.7)$ & $9(18.8)$ & \\
\hline No & $204(88.3)$ & $39(81.2)$ & \\
\hline Use of non-ACEI/ARB drugs & & & $<0.001$ \\
\hline Yes & $65(28.1)$ & $34(70.8)$ & \\
\hline No & $166(71.9)$ & $14(29.2)$ & \\
\hline Perioperative chemotherapy & & & 0.529 \\
\hline Yes & $37(16.0)$ & $8(16.7)$ & \\
\hline No & $194(84.0)$ & $40(83.3)$ & \\
\hline Tumour location & & & 0.333 \\
\hline Renal pelvis & $13 \mid(56.7)$ & $25(52.1)$ & \\
\hline Ureter & $100(43.3)$ & $23(47.9)$ & \\
\hline Tumour length & & & 0.110 \\
\hline$<30 \mathrm{~mm}$ & $139(60.2)$ & $34(70.8)$ & \\
\hline$\geqslant 30 \mathrm{~mm}$ & $92(39.8)$ & $14(29.2)$ & \\
\hline Tumour grade & & & 0.102 \\
\hline $\mathrm{GI} / 2^{\circ}$ & $85(36.8)$ & $23(47.9)$ & \\
\hline G3 & $146(63.2)$ & $25(52.1)$ & \\
\hline Pathological T stage & & & 0.112 \\
\hline$<\mathrm{pT} 3$ & $100(43.3)$ & $26(54.2)$ & \\
\hline$\geqslant \mathrm{p} T 3$ & $13 \mid(56.7)$ & $22(45.8)$ & \\
\hline Lymphovascular invasion & & & 0.145 \\
\hline Negative & $137(59.3)$ & $33(68.7)$ & \\
\hline Positive & $94(40.7)$ & $15(31.3)$ & \\
\hline Concomitant CIS & & & 0.335 \\
\hline Negative & $183(79.2)$ & $40(83.3)$ & \\
\hline Positive & $48(20.8)$ & $8(16.7)$ & \\
\hline No. of tumour metastasis & $57(24.7)$ & $4(8.3)$ & 0.008 \\
\hline No. of cancer death & $46(19.9)$ & $3(6.4)$ & 0.026 \\
\hline
\end{tabular}

Abbreviations: $\mathrm{ACEI}=$ angiotensin-converting enzyme inhibitor; $\mathrm{ARB}=$ angiotensin $\|$ receptor blocker; $\mathrm{CIS}=$ carcinoma in situ.

survival. On multivariate analysis controlling the presence of CKD, the use of ACEIs or ARBs, tumour grade, pathological T stage, and LVI, the appearance of pathological T3 $(P=0.007$, $\mathrm{HR}=3.28)$ and positive LVI $(P=0.049, \mathrm{HR}=1.96)$ were independent risk factors for a decrease in subsequent disease-specific survival, whereas the use of ACEIs or ARBs was not an 
A
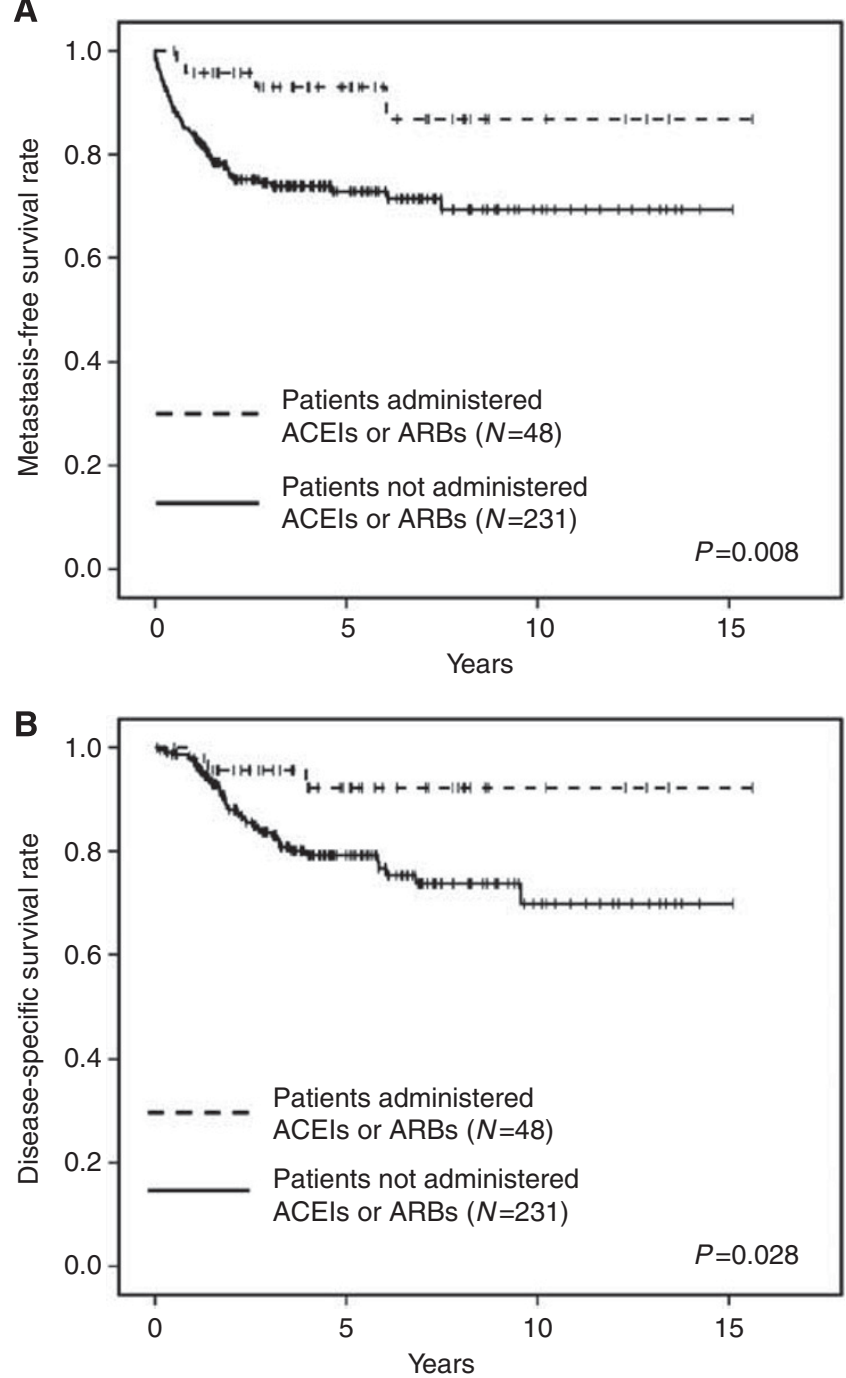

Figure I (A) Metastasis-free survival rate after nephroureterectomy in patients administered vs not administered ACEls or ARBs. (B) Diseasespecific survival rate after nephroureterectomy in patients administered vs not administered ACEls or ARBs. independent predictor of subsequent disease-specific survival. In subgroup analysis using 153 patients who had pT3 tumours, multivariate analysis also showed that no ACEI or ARB administration was an independent risk factor for a decrease in subsequent metastasis-free survival, whereas it did not independently predict disease-specific survival.

We then evaluated the associations between ACEI or ARB use and overall survival. A total of 62 subjects died during follow-up. Using Kaplan-Meier analysis, the 5-year overall survival rate was $85.8 \%$ in patients administered ACEIs and ARBs and $73.7 \%$ in their counterparts $(P=0.047)$ (Figure 2), whereas multivariate analysis showed that ACEI or ARB use did not independently predict subsequent overall survival in our population.

\section{DISCUSSION}

In the present study, we retrospectively investigated the use of RAS inhibitors (ACEIs and ARBs) and other standard prognostic factors in 279 patients who underwent nephroureterectomy for localised UTUC. Kaplan-Meier analysis revealed that patients

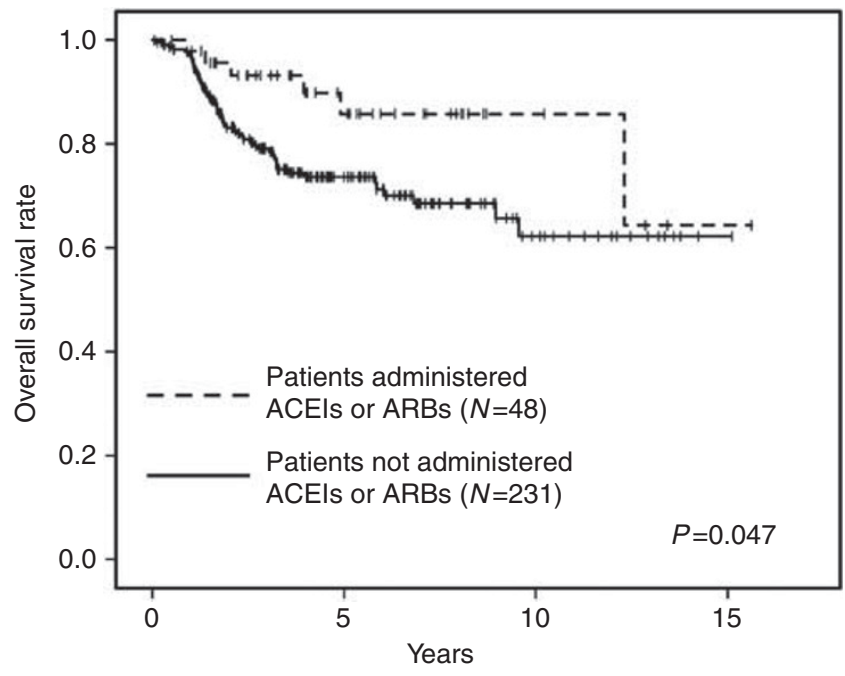

Figure 2 Overall survival rate after nephroureterectomy in patients administered vs not administered ACEls or ARBs.

Table 4 Risk factors for predicting metastasis-free and disease-specific survival following nephroureterectomy in 279 patients

\begin{tabular}{|c|c|c|c|c|c|c|}
\hline \multirow{2}{*}{ Characteristic } & \multicolumn{3}{|c|}{ Metastasis-free survival } & \multicolumn{3}{|c|}{ Disease-specific survival } \\
\hline & $\begin{array}{l}\text { Univariate } \\
P \text {-value }\end{array}$ & \multicolumn{2}{|c|}{ Multivariate } & $\begin{array}{c}\text { Univariate } \\
P \text {-value }\end{array}$ & \multicolumn{2}{|c|}{ Multivariate } \\
\hline Age ( $<70$ years vs $\geqslant 70$ years $)$ & 0.048 & & & 0.197 & & \\
\hline Gender (male vs female) & 0.105 & & & 0.249 & & \\
\hline Cardiovascular disease (yes vs no) & 0.956 & & & 0.449 & & \\
\hline Hypertension (yes vs no) & 0.553 & & & 0.874 & & \\
\hline Use of non-ACEI/ARB drugs (yes vs no) & 0.896 & & & 0.703 & & \\
\hline Use of ACEI/ARB drugs (yes vs no) & 0.013 & $3.14(1.14-8.67)$ & 0.027 & 0.039 & & \\
\hline Perioperative chemotherapy (yes vs no) & 0.009 & & & 0.122 & & \\
\hline Tumour location (renal pelvis vs ureter) & 0.124 & & & 0.575 & & \\
\hline Tumour length $(<30 \mathrm{vs} \geqslant 30 \mathrm{~mm})$ & 0.060 & & & 0.165 & & \\
\hline Tumour grade (G//2 vs G3) & 0.001 & & & 0.003 & & \\
\hline
\end{tabular}

Abbreviations: $\mathrm{ACEI}=$ angiotensin-converting enzyme inhibitor; $\mathrm{ARB}=$ angiotensin $\|$ receptor blocker; $\mathrm{Cl}=$ confidence interval; $\mathrm{ClS}=$ carcinoma in situ; $\mathrm{HR}=\mathrm{Hazard}$ ratio. 
administered ACEIs or ARBs had significantly suppressed subsequent tumour metastasis. Multivariate analysis showed that in addition to other standard prognostic factors, ACEI or ARB use was an independent predictor of a decrease in metastasis-free survival, although it did not independently predict disease-specific survival. These results suggest that RAS inhibitor administration may improve disease control by suppressing subsequent tumour metastasis following radical surgery in patients with localised UTUC.

RAS inhibitors, such as ACEIs and ARBs, are widely used to treat hypertension, and there has been an increase in the number of reports evaluating the importance of RAS inhibition in organ protection, such as in the treatment of cardiac hypertrophy, diabetic nephropathy, and diabetic retinopathy (Grandi and Maresca, 2006). With respect to anti-tumourgenesis, Lever et al in a large retrospective cohort consisting of 5207 patients reported the first clinical evidence that long-term use of ACEs induced potent protective effects against carcinogenesis, whereas no significant association was apparent with the use of other antihypertensive drugs (Lever et al, 1998). Since then, in addition to cardiovascular functions regulated by the systemic RAS, the potential role of local RAS in malignancy has been recognised (Egami et al, 2003; Juillerat-Jeanneret et al, 2004; Ager et al, 2008; George et al, 2010), and an increasing body of evidence in experimental studies suggests that Ang II could act on tumour progression via two main and different mechanisms; the promotion of cancer proliferation and/or neovascularisation through AT1R (Greco et al, 2003; Arrieta et al, 2005; Khakoo et al, 2008).

Several researchers have investigated the clinical impact of RAS inhibitors in the treatment of malignancy. With respect to carcinogenesis, Ronquist et al reported that users of ACEI captopril had a lower risk of developing prostate cancer (Ronquist et al, 2004). Christian et al conducted a randomised prospective study using 1051 patients at high risk of keratinocyte cancer, and reported that users of ACEIs or ARBs had statistically significant reduced risks of basal cell carcinoma and squamous cell carcinoma (Christian et al, 2008). However, some studies have reported no significant correlation between RAS inhibitor use and carcinogenesis in breast cancer and prostate cancer patients (Li et al, 2003; Perron et al, 2004; Fryzek et al, 2006). Sipahi et al performed metaanalysis and reported that patients receiving ARBs had a slightly but significantly higher risk of developing lung cancer $(1.2 \%)$, although no significant correlation was found in other solid cancers (Sipahi et al, 2010). Two retrospective studies also suggested the potent risk of carcinogenesis in RAS inhibitor administration (Chang et al, 2011; Opelz and Döhler, 2011). Therefore, determining the exact role of RAS inhibitors in carcinogenesis is controversial at the present time because of the existence of apparently contradictory evidence.

On the other hand, with respect to cancer treatment, a few reports evaluated the efficacy of RAS inhibitor administration, and most reported positive outcomes, especially in combination with other anti-cancer agents (Uemura et al, 2005; Wilop et al, 2009; Nakai et al, 2010; Tatokoro et al, 2011). Wilop et al analysed retrospectively 287 patients with advanced non-small cell lung cancer undergoing first-line platinum-based chemotherapy, and reported that patients receiving either ACEIs or ARBs had a median survival that was 3.1 months longer than non-recipients (11.7 vs 8.6 months) (Wilop et al, 2009). Nakai et al reported the use of ACEIs or ARBs with gemcitabine was an independent prognostic factor for both progression-free survival and overall survival in 155 patients with advanced pancreatic cancer (Nakai et al, 2010). Two prospective studies suggested RAS inhibitor administration was effective as a salvage therapy in the treatment of prostate cancer and renal cell cancer (Uemura et al, 2005; Tatokoro et al, 2011).

However, few studies have evaluated the possible role of RAS inhibitors as an adjuvant treatment following initial therapy.
Yoshiji et al presented clinical evidence demonstrating that inhibition of RAS contributed to the suppression of tumour recurrence (Yoshiji et al, 2009). They demonstrated that ACEIs in combination with vitamin $\mathrm{K}$ suppressed the recurrence of hepatocellular carcinoma after curative therapy, although the exact impact of a single ACEI agent by itself could not be fully evaluated due to the limited number of patients in the study.

For patients with UTUC, local recurrence following radical surgery is rare and the risk of distant metastasis is directly related to subsequent prognosis (Rouprêt et al, 2011). To improve prognostic outcomes in high-risk UTUC, perioperative chemotherapy has been considered in both neoadjuvant and adjuvant settings (Hellenthal et al, 2009; Matin et al, 2010). However, limitations of a chemotherapeutic approach include the probability that some patients may not tolerate both chemotherapy and surgery (Kaag et al, 2010; Lane et al, 2010). Poor renal function following nephroureterectomy may also preclude the effective dose and/or administration of chemotherapeutic agents (Kaag et al, 2010). Thus, a new strategy that is both effective and possesses adequate tolerability would be a very important breakthrough in the adjuvant setting following nephroureterectomy. The present study may provide a potent aspect of RAS inhibitors as an effective treatment in UTUC.

Although tumour metastasis is affected by many factors, it may be controversial as to whether RAS regulation is a key mechanism involved in suppressing tumour metastasis. Our recent work has found that Ang II-AT1R signalling can have an effect on the tumour microenvironment by promoting macrophage mobilisation and infiltration into the tumour bed via signalling pathways involving monocyte chemoattractant protein-1 (MCP-1) (Shirotake et al, 2011a). MCP-1 has been identified as a prominent regulator of the growth, survival, invasiveness, and migration of tumour cells (Egami et al, 2003; Li et al, 2009). Therefore, we believe that the regulation of RAS may potentially function to suppress subsequent tumour metastasis following surgery. However, in the present study, the use of RAS inhibitors could not independently predict disease-specific survival. We propose that one of the reasons might be the lack of CDDP-based chemotherapy after tumour metastasis. Focusing on patients who had tumour metastasis in our population, although half of the patients in the RAS inhibitor group did not receive CDDP-based regimens, $64.9 \%$ of the patients not administered RAS inhibitors were administered CDDP-based chemotherapy after tumour metastasis. This could be one of limitations in the study.

There is also another limitation. First, it was performed in a retrospective manner, and unknown sources of bias may exist in the findings. Due to the limited sample size of patients with ACEIs or ARBs, we could not fully evaluate the differences in doses or types of ACEIs and ARBs. Although the other antihypertensive drugs used consisted mainly of calcium-channel blockers and $\beta$-blockers or diuretics administered in a few patients, we did not fully evaluate the exact impact of $\beta$-blockers and diuretics on survival. We did not determine accurate compliance rates with respect to their medication or validate their compliance because our data were obtained using the information from patient interviews. In addition, we did not fully evaluate the pre-operative duration or past history of RAS inhibitor administration, although the hypertension in most of the patients administered RAS inhibitors had already been treated for a mean of 8.6 years duration pre-operatively. Not all patients received neoadjuvant and adjuvant chemotherapy, which may have had an effect on subsequent tumour progression. Thus, a prospective study with a larger population would be warranted in order to clarify the accurate prognostic role of RAS inhibitors in the treatment of UTUC.

In summary, the results of our retrospective analysis suggest that RAS inhibitor administration may improve prognostic outcomes in patients with UTUC. As RAS inhibitors are already used 
as antihypertensive drugs without severe side effects, we propose from a clinical point of view that they may be an effective choice in the treatment of patients with localised UTUC following nephroureterectomy.

\section{ACKNOWLEDGEMENTS}

This work was supported in part by Grants-in-Aid for Scientific Research (\#22791495 to Tanaka N and \#22591777 to Miyajima A) from the Ministry of Education, Culture, Sports, Science, and Technology of Japan. This work was also supported in part by Keio University Grant-in-Aid for Encouragement of Young Medical Scientists (\#002-002-0005 to Tanaka N) from Keio University School of Medicine.

\section{Conflict of interest}

The authors declare no conflict of interest.

\section{REFERENCES}

Ager EI, Neo J, Christophil C (2008) The renin-angiotensin system and malignancy. Carcinogenesis 29: 1675-1684

Arrieta O, Guevara P, Escobar E, García-Navarrete R, Pineda B, Sotelo J (2005) Blockade of angiotensin II type 1 receptor decreases the synthesis of growth factors and induces apoptosis in C6 cultured cells and C6 rat glioma. Br J Cancer 92: $1247-1252$

Chang CH, Lin JW, Wu LC, Lai MS (2011) Angiotensin receptor blockade and risk of cancer in type 2 diabetes mellitus: a nationwide case-control study. J Clin Oncol 29: 3001-3007

Christian JB, Lapane KL, Hume AL, Eaton CB, Weinstock MA, VATTC Trial (2008) Association of ACE inhibitors and angiotensin receptor blockers with keratinocyte cancer prevention in the randomized VATTC trial. I Natl Cancer Inst 100: $1223-1232$

Egami K, Murohara T, Shimada T, Sasaki K, Shintani S, Sugaya T, Ishii M, Akagi T, Ikeda H, Matsuishi T, Imaizumi T (2003) Role of host angiotensin II type 1 receptor in tumor angiogenesis and growth. J Clin Invest 112: 67-75 Favaretto RL, Shariat SF, Chade DC, Godoy G, Adamy A, Kaag M, Bochner $\mathrm{BH}$, Coleman J, Dalbagni G (2010) The effect of tumor location on prognosis in patients treated with radical nephroureterectomy at Memorial Sloan-Kettering Cancer Center. Eur Urol 58: 574-580

Fryzek JP, Poulsen AH, Lipworth L, Pedersen L, Nørgaard M, McLaughlin JK, Friis S (2006) A cohort study of antihypertensive medication use and breast cancer among Danish women. Breast Cancer Res Treat 97: 231-236

George AJ, Thomas WG, Hannan RD (2010) The renin-angiotensin system and cancer: old dog, new tricks. Nat Rev Cancer 10: 745-759

Grandi AM, Maresca AM (2006) Blockade of the renin-angiotensinaldosterone system: effects on hypertensive target organ damage. Cardiovasc Hematol Agents Med Chem 4: 219-228

Greco S, Muscella A, Elia MG, Salvatore P, Storelli C, Mazzotta A, Manca C, Marsigliante S (2003) Angiotensin II activates extracellular signal regulated kinases via protein kinase $\mathrm{C}$ and epidermal growth factor receptor in breast cancer cells. J Cell Physiol 196: 370-377

Hall MC, Womack S, Sagalowsky AI, Carmody T, Erickstad MD, Roehrborn CG (1998) Prognostic factors, recurrence, and survival in transitional cell carcinoma of the upper urinary tract: a 30-year experience in 252 patients. Urology 52: 594-601

Hellenthal NJ, Shariat SF, Margulis V, Karakiewicz PI, Roscigno M, Bolenz C, Remzi M, Weizer A, Zigeuner R, Bensalah K, Ng CK, Raman JD, Kikuchi E, Montorsi F, Oya M, Wood CG, Fernandez M, Evans CP, Koppie TM (2009) Adjuvant chemotherapy for high risk upper tract urothelial carcinoma: results from the Upper Tract Urothelial Carcinoma Collaboration. J Urol 182: 900 -906

Holmang S, Johansson SL (2005) Urothelial carcinoma of the upper urinary tract: comparison between the WHO/ISUP 1998 consensus classification and WHO 1999 classification system. Urology 66: 274-278

Jemal A, Siegel R, Xu J, Ward E (2011) Cancer statistics, 2010. CA Cancer J Clin 61: 133-134

Juillerat-Jeanneret L, Celerier J, Chapuis Bernasconi C, Nguyen G, Wostl W, Maerki HP, Janzer RC, Corvol P, Gasc JM (2004) Renin and angiotensinogen expression and functions in growth and apoptosis of human glioblastoma. Br J Cancer 90: 1059-1068

Kaag MG, O'Malley RL, O'Malley P, Godoy G, Chen M, Smaldone MC, Hrebinko RL, Raman JD, Bochner B, Dalbagni G, Stifelman MD, Taneja SS, Huang WC (2010) Changes in renal function following nephroureterectomy may affect the use of perioperative chemotherapy. Eur Urol 58: 581-587

Khakoo AY, Sidman RL, Pasqualini R, Arap W (2008) Does the reninangiotensin system participate in regulation of human vasculogenesis and angiogenesis? Cancer Res 68: $9112-9115$
Kondo T, Nakazawa H, Ito F, Hashimoto Y, Toma H, Tanabe K (2007) Primary site and incidence of lymph node metastases in urothelial carcinoma of upper urinary tract. Urology 69: 265-269

Kosaka T, Miyajima A, Takayama E, Kikuchi E, Nakashima J, Ohigashi T, Asano T, Sakamoto M, Okita H, Murai M, Hayakawa M (2007) Angiotensin II type 1 receptor antagonist as an angiogenic inhibitor in prostate cancer. Prostate 67: 41-49

Kosugi M, Miyajima A, Kikuchi E, Horiguchi Y, Murai M (2006) Angiotensin II type 1 receptor antagonist candesartan as an angiogenic inhibitor in a xenograft model of bladder cancer. Clin Cancer Res 12: $2888-2893$

Lane BR, Smith AK, Larson BT, Gong MC, Campbell SC, Raghavan D, Dreicer R, Hansel DE, Stephenson AJ (2010) Chronic kidney disease after nephroureterectomy for upper tract urothelial carcinoma and implications for the administration of perioperative chemotherapy. Cancer 116: $2967-2973$

Lever AF, Hole DJ, Gillis CR, McCallum IR, McInnes GT, MacKinnon PL, Meredith PA, Murray LS, Reid JL, Robertson JW (1998) Do inhibitors of angiotensin-1-converting enzyme protect against risk of cancer? Lancet 352: $179-184$

Levey AS, Bosch JP, Lewis JB, Greene T, Rogers N, Roth D (1999) A more accurate method to estimate glomerular filtration rate from serum creatinine: a new prediction equation. Modification of Diet in Renal Disease Study Group. Ann Intern Med 130: $461-470$

Li CI, Malone KE, Weiss NS, Boudreau DM, Cushing-Haugen KL, Daling JR (2003) Relation between use of antihypertensive medications and risk of breast carcinoma among women ages 65-79 years. Cancer 98: $1504-1513$

Li X, Loberg R, Liao J, Ying C, Snyder LA, Pienta KJ, McCauley LK (2009) A destructive cascade mediated by CCL2 facilitates prostate cancer growth in bone. Cancer Res 69: 1685-1692

Margulis V, Shariat SF, Matin SF, Kamat AM, Zigeuner R, Kikuchi E, Lotan Y, Weizer A, Raman JD, Wood CG, Upper Tract Urothelial Carcinoma Collaboration (2009) Outcomes of radical nephroureterectomy: a series from the Upper Tract Urothelial Carcinoma Collaboration. Cancer 115: $1224-1233$

Matin SF, Margulis V, Kamat A, Wood CG, Grossman HB, Brown GA, Dinney CP, Millikan R, Siefker-Radtke AO (2010) Incidence of downstaging and complete remission after neoadjuvant chemotherapy for high-risk upper tract transitional cell carcinoma. Cancer 116: 3127-3134

Miyajima A, Kosaka T, Asano T, Asano T, Seta K, Kawai T, Hayakawa M (2002) Angiotensin II type 1 antagonist prevents pulmonary metastasis of murine renal cancer by inhibiting tumor angiogenesis. Cancer Res 62: $4176-4179$

Miyake H, Hara I, Gohji K, Arakawa S, Kamidono S (1998) The significance of lymphadenectomy in transitional cell carcinoma of the upper urinary tract. BJU Int 82: $494-498$

Nakai Y, Isayama H, Ijichi H, Sasaki T, Sasahira N, Hirano K, Kogure H, Kawakubo K, Yagioka H, Yashima Y, Mizuno S, Yamamoto K, Arizumi T, Togawa O, Matsubara S, Tsujino T, Tateishi K, Tada M, Omata M, Koike K (2010) Inhibition of renin-angiotensin system affects prognosis of advanced pancreatic cancer receiving gemcitabine. Br J Cancer 103: 1644-1648

National Kidney Foundation (2002) K/DOQI clinical practice guidelines for chronic kidney disease: evaluation, classification, and stratification. Am J Kidney Dis 39: S1-S266

Opelz G, Döhler B (2011) Treatment of kidney transplant recipients with ACEi/ARB and risk of respiratory tract cancer: A Collaborative Transplant Study Report. Am J Transplant 11: 2483-2489 
Perron L, Bairati I, Harel F, Meyer F (2004) Antihypertensive drug use and the risk of prostate cancer (Canada). Cancer Causes Control 15: 535-541

Ronquist G, Rodríguez LA, Ruigómez A, Johansson S, Wallander MA, Frithz G, Svärdsudd K (2004) Association between captopril, other antihypertensive drugs and risk of prostate cancer. Prostate 58: 50-56

Rouprêt M, Zigeuner R, Palou J, Boehle A, Kaasinen E, Sylvester R, Babjuk M, Oosterlinck W (2011) European Guidelines for the Diagnosis and Management of Upper Urinary Tract Urothelial Cell Carcinomas: 2011 Update. Eur Urol 59: 584-594

Shirotake S, Miyajima A, Kosaka T, Tanaka N, Kikuchi E, Mikami S, Okada Y, Oya M (2011a) Regulation of monocyte-chemoattractant protein-1 through angiotensin II type 1 receptor in prostate cancer. Am J Pathol (in press)

Shirotake S, Miyajima A, Kosaka T, Tanaka N, Maeda T, Kikuchi E, Oya M (2011b) Angiotensin II type 1 receptor expression and microvessel density in human bladder cancer. Urology 77(4): 1009.e19-1009.e25

Sipahi I, Debanne SM, Rowland DY, Simon DI, Fang JC (2010) Angiotensinreceptor blockade and risk of cancer: meta-analysis of randomized control trials. Lancet Oncol 11: 627-636

Tanaka N, Miyajima A, Kosaka T, Shirotake S, Hasegawa M, Kikuchi E, Oya M (2010) Cis-dichlorodiammineplatinum upregulates angiotensin II type 1 receptors through reactive oxygen species generation and enhances VEGF production in bladder cancer. Mol Cancer Ther 9: 2982-2992

Tatokoro M, Fujii Y, Kawakami S, Saito K, Koga F, Matsuoka Y, Iimura Y, Masuda H, Kihara K (2011) Phase-II trial of combination treatment of interferon-á, cimetidine, cyclooxygenase-2 inhibitor and renin-angiotensin-system inhibitor (I-CCA therapy) for advanced renal cell carcinoma. Cancer Sci 102: 137-143

Uemura H, Hasumi H, Kawahara T, Sugiura S, Miyoshi Y, Nakaigawa N, Teranishi J, Noguchi K, Ishiguro H, Kubota Y (2005) Pilot study of angiotensin II receptor blocker in advanced hormone-refractory prostate cancer. Int J Clin Oncol 10: 405-410

Wilop S, von Hobe S, Crysandt M, Esser A, Osieka R, Jost E (2009) Impact of angiotensin I converting enzyme inhibitors and angiotensin II type 1 receptor blockers on survival in patients with advanced non-smallcell lung cancer undergoing first-line platinum-based chemotherapy. J Cancer Res Clin Oncol 135: 1429-1435

Yoshiji H, Noguchi R, Toyohara M, Ikenaka Y, Kitade M, Kaji K, Yamazaki M, Yamao J, Mitoro A, Sawai M, Yoshida M, Fujimoto M, Tsujimoto T, Kawaratani H, Uemura M, Fukui H (2009) Combination of vitamin $\mathrm{K} 2$ and angiotensin-converting enzyme inhibitor ameliorates cumulative recurrence of hepatocellular carcinoma. J Hepatol 51: 315-321

This work is published under the standard license to publish agreement. After 12 months the work will become freely available and the license terms will switch to a Creative Commons Attribution-NonCommercial-Share Alike 3.0 Unported License. 